\title{
Proposta de Estrutura Combinada para Análise da Competitividade e da Sustentabilidade de Cidades ${ }^{1}$
}

\author{
Proposed Structure for Competitiveness and Sustainability \\ Combined Analysis of Cities
}

\section{Estructura Propuesta para el Análisis Combinado de la Competitividad y la Sostenibilidad de las Ciudades}

\author{
Eduardo Codevilla Soares, Msc. \\ Pontifícia Universidade Católica do Rio Grande do Sul \\ Faculdade de Administração Contabilidade e Economia \\ Endereço: Rua J.K. de Oliveira, 600, Bl. 03, Ap. 109 - Porto - \\ Pelotas - RS - CEP 96080-000 \\ Telefone: 55-53-8105-5393, \\ E-mail: eduardo@cosig.com.br
}

\author{
Peter Bent Hansen, Dr. \\ Pontifícia Universidade Católica do Rio Grande do Sul \\ Faculdade de Administração Contabilidade e Economia \\ Programa de Pós-Graduação em Administração \\ Endereço completo: Av. Ipiranga, 6681, prédio 50, 11ํ., sala \\ 1105 - Partenon - Porto Alegre - RS - CEP 90619-900, \\ Telefone: 55-51-3320-3524 \\ E-mail: peter.hansen@pucrs.br
}

\section{RESUMO}

O crescimento econômico de meados do século XX e início do século XXI, descortinou uma série de problemas os quais tornaram-se preocupações na atualidade, entre outros, os problemas ambientais e sociais. Tendo como embasamento a discussão sobre os dois paradigmas predominantes nesse contexto, a abordagem de Maximização de Lucros dos Shareholders (MLS) e a abordagem da Responsabilidade Social Corporativa (RSC), o objetivo deste artigo é lançar um novo olhar sobre os temas visando permitir uma aproximação dos constructos teóricos que aparentemente se mostram divergentes, e evidenciar a relevância de se considerar os conceitos de sustentabilidade na construção da competitividade das cidades. Para desenvolvimento desta pesquisa foram realizadas entrevistas e desenvolvidos mapas cognitivos com especialistas e atores sociais de cidades do RS, os quais convivem com tal contexto em seu cotidiano. Como resultado do trabalho desenvolvido constata-se que uma abordagem conjunta entre competitividade e sustentabilidade é possível de ser realizada, desde que sejam consideradas as divergências fundamentais entre os dois campos.

Palavras-chave: Competitividade. Responsabilidade Social Corporativa. Sustentabilidade.

\section{ABSTRACT}

The economic growth of the mid-twentieth century and early twenty-first century ushered a number of problems that have become concerns at present, among others, environmental and social problems. Taking as a base for discussion of the two predominant paradigms in this context, the approach of Profit Maximization of Shareholders ( MLS ) and Corporate Social Responsibility (CSR) approach, the aim of this article is to take a fresh look on the subjects allowing for an approximation theoretical constructs that apparently show divergent, and highlight the importance of considering the concepts of sustainability in building the competitiveness of

\footnotetext{
${ }^{1}$ Artigo recebido em 10.01.2014. O presente estudo foi selecionado através do processo de Fast Track do II Simpósio Internacional de Gestão de Projetos (SINGEP) - e I Simpósio Internacional de Inovação e Sustentabilidade (S2IS) 2013. Recomendado para publicação por José Ribamar Marques de Carvalho (Editor Científico). Publicado em 10.04.2014. Organização responsável UACC/CCJS/UFCG.
} 
cities. To develop this research developed cognitive maps and interviews with experts and social actors cities of $R S$, which coexist with this context in their daily lives were taken. As a result of the work it was found that a joint approach between competitiveness and sustainability can be realized, provided they are considered the fundamental differences between the two fields.

Keywords: Competitiveness. Corporate Social Responsibility. Sustainability. RESUMEN

El crecimiento económico de la segunda mitad del siglo XX y principios del siglo XXI marcó el comienzo de una serie de problemas que se han convertido en preocupaciones en la actualidad, entre otros, los problemas ambientales y sociales. Tomando como base para la discusión de los dos paradigmas predominantes en este contexto, el enfoque de maximización del beneficio de los Accionistas (MLS) y el enfoque de la Responsabilidad Social Corporativa (RSC), el objetivo de este artículo es dar una nueva mirada sobre los temas que permitan una aproximación construcciones teóricas que aparentemente muestran divergentes, y ponen de relieve la importancia de considerar los conceptos de sostenibilidad en la construcción de la competitividad de las ciudades. Para desarrollar esta investigación desarrolló los mapas cognitivos y entrevistas con expertos y actores sociales ciudades de RS, que conviven con este contexto en su vida cotidiana fueron tomadas. Como resultado del trabajo se encontró que un enfoque conjunto entre la competitividad y la sostenibilidad se puede realizar, siempre y cuando se consideran las diferencias fundamentales entre los dos campos.

Palabras clave: Competitividad. Responsabilidad Social Corporativa. Sostenibilidad.

\section{INTRODUÇÃO}

A partir de meados do século $X X$, e com ainda mais força ainda no início do século XXI, o processo de globalização fez com que o mundo passasse a ser visto como uma aldeia interligada, com muitas relações de interdependências sociais, econômicas e políticas entre países, regiões e empresas.

Essas interdependências, conforme a concepção da "aldeia global", seriam teoricamente, capazes de estabelecer ciclos de dependência mútua entre as regiões, criando assim um contexto de solidariedade e de busca por ideais comuns, sejam estes ambientais, econômicos, empresariais, sociais ou outros. Nesse contexto, a procura das organizações por mercados em âmbito global seria capaz de equalizar as relações socioeconômicas entre as regiões e, com disso, promover a integração entre as regiões desenvolvidas e as demais.

Contudo, algumas características adjacentes ao processo de globalização, como a maior facilidade de fluência de informações, o maior acesso a novas tecnologias, a interdependência dos países e os caminhos das relações de consumo, trouxeram como consequência, ao invés da esperada homogeneização do espaço mundial, o contrário. As cidades, então especializadas e algumas consideradas como grandes polos produtivos, passaram a oferecer diferenciais, ou benefícios notórios, às organizações que se instalam ou se desenvolvem em seus territórios, sendo que algumas delas tornaram-se, por si só, fontes de vantagens concorrenciais (SANTOS, 1997). 
O grande crescimento econômico das organizações, regiões e nações, ocorrido nos séculos XX e XXI, apesar de gerar riquezas e disponibilidade de recursos financeiros, trouxe consigo uma série de problemas como os problemas sociais e ambientais entre outros. Tais problemas conduziram a reflexões a respeito do papel das organizações e dos governos nas sociedades.

Para Senge et al. (2007) os problemas sociais e ambientais, tradicionalmente são tratados como externalidades da atividade econômica em si e, por definição, necessitam de atenção dos governos. Contudo, segundo o mesmo autor, por uma série de fatores os governos já não são capazes de enfrentar tais problemas. Por outro lado, Krishnan (2011) argumenta que dois paradigmas são predominantes na discussão a respeito do papel das organizações na sociedade: (1) a abordagem da Maximização de Lucros dos Shareholders (MLS) e, (2) a abordagem da Responsabilidade Social Corporativa (RSC). Este autor aborda que um diálogo entre esses campos (MLS e RSC) só é possível após reconhecerem-se as diferenças fundamentais entre os mesmos.

O paradigma MLS segue definições baseadas na visão de Friedman (1971), que em sua obra mais aclamada sugeriu que a única responsabilidade social de uma empresa é a sua capacidade de aumentar os lucros e assim maximizar a riqueza de seus Shareholders. Esta tem sido a abordagem empregada por muitos economistas e acadêmicos de finanças, que argumentam que a maximização lucros dos Shareholders deve ser vista como o objetivo normativo e ideal, no qual todas as decisões de negócios devem ser baseadas. Esta visão é corroborada também por outros autores como Sternberg (1999) e Jensen (2001). Segundo esta perspectiva, a maximização do lucro das organizações leva também, por consequência, à maximização da riqueza da sociedade (KRISHNAN, 2011).

O paradigma da RSC assume que devido à reunião de vários fatores como o tamanho das organizações, a disponibilidade de recursos, o acesso à tecnologia e outros, as empresas precisam realizar medidas específicas para garantirem recompensas justas e compensações a todos os Stakeholders, de forma a trazerem benefícios adicionais à sociedade além do oferecimento apenas de seus bens e serviços.

Tendo em vista as diferentes perspectivas a respeito da atratividade dos territórios para as empresas, o acirramento do processo de globalização, o consequente processo de diferenciação e especialização das cidades, e os problemas sociais e ambientais decorrentes desses fatores, este artigo tem como foco a análise da competitividade sistêmica em nível das cidades e suas relações com a sustentabilidade. Desta forma busca integrar os elementos da competitividade e da sustentabilidade, possibilitando assim o desenvolvimento de uma estrutura que permita a formulação de estratégias que contribuam para o desenvolvimento integrado das cidades. Neste contexto, o presente artigo é um convite a reflexão: como contemplar noções de sustentabilidade na análise da competitividade sistêmica das cidades? 
$\mathrm{Na}$ próxima seção são abordados inicialmente os conceitos de espaço, território, região e cidades. Em sequência são considerados os conceitos e construtos de competitividade, sendo também discutidas as abordagens referentes à Responsabilidade Social Corporativa (RSC) e à Sustentabilidade. As ferramentas de análise da sustentabilidade e os construtos de análise da competitividade são discutidos e então interpretados conjuntamente, buscando assim desenvolver uma visão abrangente a respeito das dimensões, fatores e indicadores que compõem este contexto. Posteriormente, são apresentados os aspectos metodológicos desta pesquisa e, em seguida, é realizada uma análise comparativa a respeito das interpretações de atores sociais e especialistas em relação ao tema, bem como de suas respostas referentes aos pontos pesquisados. Por fim, são tecidas as considerações finais a respeito dos resultados obtidos da integração proposta, limitações da pesquisa e sugestões para estudos futuros.

\section{REFERENCIAL TEÓRICO}

\subsection{Cidades, Competitividade e Sustentabilidade}

Para a análise de fatores que influenciam a competitividade de uma região, faz-se necessária a compreensão do conceito de espaço, tendo em vista que, conforme Santos (1997), uma região é classificada como um subespaço do espaço nacional total.

Para o autor, o espaço, em sua totalidade, é:

[...] formado por um conjunto indissociável, solidário e também contraditório, de sistemas de objetos e sistemas de ações, não considerados isoladamente, mas como o quadro único no qual a história se dá (SANTOS, 1997, p.39).

Santos e Silveira (2001) compreendem o território como uma mediação entre o mundo e a sociedade nacional e local. Para eles, o território deve ser considerado em suas divisões jurídico-políticas, heranças históricas e atuais conteúdos econômicos, financeiros, culturais, fiscais e normativos, os quais dão conteúdo as suas regiões.

Assim sendo, o território pode ser caracterizado por seus aspectos sociais, culturais e econômicos. É tanto o resultado do processo histórico quanto da base material e social das novas ações humanas (SANTOS, 1997). Levando em consideração que o espaço, tal como abordado no presente artigo, e que o território é compreendido como o espaço utilizado e apropriado, caracterizado por aspectos sociais, culturais e econômicos tal como abordado por Santos (1997) e Raffestin (1993), para fins deste estudo, uma cidade é conceituada como um subespaço do território nacional. Discute-se a seguir o tema da competividade.

\subsection{Competitividade}


A grande dificuldade em observar todos os fatores que influenciam a competitividade e seu caráter multidisciplinar, faz com que existam várias abordagens a respeito do tema. Dessa maneira, muitos conceitos e enfoques foram desenvolvidos na tentativa de oferecer uma definição de competitividade. Assim sendo, é necessária a observação dos conceitos que formam uma linha de pensamento que corresponda ao contexto contemporâneo, para que seja possível formular um conceito comum e condizente com os fatores preponderantes na atualidade. Desta maneira, o Quadro 1 exibe de forma sumarizada as abordagens da competitividade utilizadas neste artigo.

\begin{tabular}{|l|l|l|}
\hline \multicolumn{1}{|c|}{ Autor } & \multicolumn{1}{c|}{ Enfoque } & \multicolumn{1}{c|}{ Abordagem } \\
\hline Porter (1990) & Produtividade nacional & Nação \\
\hline Esser et al. (1995) & $\begin{array}{l}\text { Interação de vários fatores (Enfoque sistêmico) } \\
\text { para obtenção de vantagem competitiva }\end{array}$ & $\begin{array}{l}\text { Setores, indústrias e } \\
\text { firmas. }\end{array}$ \\
\hline Esterhuizen et al. (2008) & Crescimento Sustentado & Setor econômico \\
\hline Coutinho e Ferraz (2002) & $\begin{array}{l}\text { Formular e implementar estratégias } \\
\text { concorrenciais }\end{array}$ & Firma (empresa) \\
\hline Chikán (2008) & Produtividade Sustentada & Produto \\
\hline Slack (1993) & Vantagens em manufatura & \multicolumn{2}{|l}{} \\
\hline $\begin{array}{l}\text { Feurer e Chaharbaghi } \\
\text { (1994) }\end{array}$ & $\begin{array}{l}\text { Da capacidade de persuadir clientes para a possibilidade de melhorar } \\
\text { capacidades organizacionais }\end{array}$ \\
\hline
\end{tabular}

Quadro 1 - Algumas abordagens contemporâneas da competitividade.

Fonte: os autores.

Destaca-se que o tema sustentabilidade, quando empregado pelos autores como Esterhuizen, Rooyen e D’haese (2008) e Chikán (2008), está atrelado a um conceito restrito a aspectos financeiros ou econômicos. O que fica evidente nestes autores mencionados, é que o conceito de competitividade não se preocupa em incorporar aspectos sociais ou ambientais como parte do papel das organizações na sociedade.

Conforme Dorneles (2011), os modelos de análise da competitividade que possuem abordagem em nível de país são os modelos GDI - German Development Institute, IMD - International Institute for Management Development; GCR - Global Competitiveness Report, Modelo Diamante de Porter, Modelo da Necessidade e Suficiência da Competitividade e Modelo da Conexão da Competitividade Nacional e da Firma. O resumo das abordagens desta autora são apresentados no Quadro 2.

A fim de compor uma análise comparativa entre os modelos expostos, faz-se necessário que algumas considerações sejam apresentadas, entre as quais a de que os conceitos de competitividade empregados nos modelos possuem divergências devido às suas diferentes dimensões, enfoques, objetivos e elementos. Tais fatores fazem com que os modelos de análise da competitividade em análise, com enfoque específico em nações, apresentem diferenças fundamentais baseadas em seus contextos de formulação. 
Com o objetivo de relacionar os critérios analisados segundo similaridades em seus conceitos e objetivos, conforme apresentados por seus autores, foram estipulados níveis de análises (paralelos) para a observação de como cada modelo dispõe suas dimensões frente às diferentes concepções dos elementos da competitividade em nível de regiões. Os níveis de análise mencionados referem-se a: (i) nível normas e padrões, leis, políticas e gestão pública; (ii) nível estrutural; e (iii) nível empresarial.

\begin{tabular}{|c|c|c|c|c|}
\hline Abor. & Framework & Enfoques & Dimensões & Autores \\
\hline \multirow{6}{*}{$\stackrel{n}{\pi}$} & GDI & Sistêmico & Meta, Macro, Meso e Micro & Esser et al. (1995) \\
\hline & IMD & \multirow{5}{*}{ 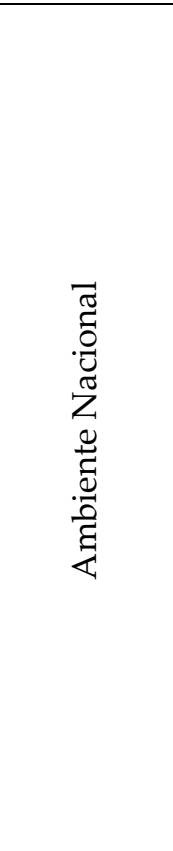 } & Políticas, Sociais e Culturais & $\begin{array}{l}\text { Rosselet-McCauley } \\
\text { (2011) }\end{array}$ \\
\hline & GCR & & $\begin{array}{l}\text { Fatores direcionadores das } \\
\text { economias; direcionadores } \\
\text { de eficiência das economias; } \\
\text { direcionadores da inovação } \\
\text { das economias }\end{array}$ & $\begin{array}{l}\text { World Economic Forum } \\
\text { (2011) }\end{array}$ \\
\hline & Diamante & & $\begin{array}{l}\text { Condições de fatores; } \\
\text { Condições de demanda; } \\
\text { Indústrias correlatas e de } \\
\text { apoio; Estratégia, estrutura } \\
\text { e rivalidade das empresas. }\end{array}$ & Porter (1990) \\
\hline & $\begin{array}{l}\text { Necessidade e } \\
\text { Suficiência da } \\
\text { Competitividade }\end{array}$ & & Micro e Macro & Ezeala-Harrison (2005) \\
\hline & $\begin{array}{l}\text { Conexão da } \\
\text { Competitividade } \\
\text { Nacional e da Firma }\end{array}$ & & $\begin{array}{l}\text { Governo e Capacidade da } \\
\text { firma }\end{array}$ & Chikán (2008) \\
\hline
\end{tabular}

Quadro 2 - Comparativo dos frameworks de competitividade

Fonte: Adaptado de Dorneles (2011, p.52)

O nível de análise que reúne as normas, padrões, leis, políticas e gestão pública, abrange os fatores sobre os quais as sociedades, mediante a articulação dos atores sociais, possuem influência na competitividade de uma cidade. Traçando um paralelo entre os modelos analisados, nesse nível de análise, é possível extrair quatro categorias que apresentam maiores similaridades entre os fatores apontados por cada modelo de análise. Nesse sentido as categorias mencionadas são: fatores socioculturais, políticas, leis e gestão pública.

O nível de análise estrutural busca delimitar as dimensões elencadas pelos autores dos modelos, que possuem o objetivo de analisar as características, natureza e qualidade dos relacionamentos dos atores sociais que interferem na competitividade de uma cidade. A análise conjunta dos modelos estudados sob essa perspectiva (Estrutural) possibilita reunir os fatores apontados pelos autores dos modelos em dez categorias: emprego, empregabilidade, saúde, educação, ciência e tecnologia, infraestrutura básica, instituições públicas, fatores externos às empresas, economia interna e economia externa. 
Considerando o nível de análise empresarial, este se refere à organização, gestão e demais características das empresas de uma determinada cidade. A análise conjunta dos modelos verificados, sob essa perspectiva (Empresarial), possibilita reunir os fatores apontados pelos autores dos modelos em uma categoria. Nesse sentido, a categoria mencionada é denominada fatores internos às empresas. Esta categoria refere-se à gestão e às características internas das empresas de uma cidade. O Quadro 3 exibe as dimensões e as categorias estruturadas para a investigação da competitividade das cidades, conforme análise proposta no presente estudo.

\begin{tabular}{|c|c|c|c|}
\hline $\begin{array}{l}\text { Nível de } \\
\text { análise }\end{array}$ & Categorias & Modelos & Autores \\
\hline \multirow{4}{*}{$\begin{array}{l}\text { Normas, } \\
\text { padrões, leis, } \\
\text { políticas e } \\
\text { gestão pública }\end{array}$} & Fatores socioculturais & \multirow{4}{*}{$\begin{array}{l}\text { Conexão da } \\
\text { competitividade Nac. } \\
\text { e da firma, IMD e } \\
\text { GDI }\end{array}$} & \multirow{4}{*}{$\begin{array}{l}\text { Esser et al. (1995), Rosselet- } \\
\text { McCauley (2011), Chikán } \\
\text { (2008) }\end{array}$} \\
\hline & Políticas & & \\
\hline & Leis & & \\
\hline & Gestão pública & & \\
\hline \multirow{11}{*}{ Estrutural } & Emprego & \multirow{11}{*}{$\begin{array}{l}\text { IMD, GCR, } \\
\text { Diamante, } \\
\text { Necessidade e } \\
\text { Suficiência da } \\
\text { Competiv., Conexão } \\
\text { da Competitividade } \\
\text { Nac. e da Firma }\end{array}$} & \multirow{11}{*}{$\begin{array}{l}\text { Rosselet-McCauley (2011), } \\
\text { Chikán (2008), World } \\
\text { Economic Forum (2011), Porter } \\
\text { (1990), Ezeala-Harrison } \\
\text { (2005) }\end{array}$} \\
\hline & Empregabilidade & & \\
\hline & $\begin{array}{l}\text { Fatores externos as } \\
\text { empresas }\end{array}$ & & \\
\hline & Saúde & & \\
\hline & Educação & & \\
\hline & Ciência & & \\
\hline & Tecnologia & & \\
\hline & Infraestrutura básica & & \\
\hline & Instituições Públicas & & \\
\hline & Economia interna & & \\
\hline & Economia externa & & \\
\hline Empresarial & $\begin{array}{l}\text { Fatores internos às } \\
\text { empresas }\end{array}$ & $\begin{array}{l}\text { GDI, GCR, IMD, } \\
\text { Conexão da } \\
\text { Competitividade } \\
\text { Nac. e da firma, } \\
\text { Diamante. }\end{array}$ & $\begin{array}{l}\text { Esser et al. (1995), WEF } \\
\text { (2011), Rosselet-McCauley } \\
\text { (2011), Chikán (2008), Porter } \\
\text { (1990) }\end{array}$ \\
\hline
\end{tabular}

Quadro 3 - Análise comparativa da competitividade

Fonte: os autores.

\subsection{Responsabilidade Social Corporativa e Sustentabilidade}

Van Bellen (2002) identifica as ferramentas Ecological Footprint (EF), Dashboard of sustainability (DS) e Barometer of sustainability (BS), como sendo as mais relevantes no contexto internacional contemporâneo. Frente a essa constatação, os três modelos são analisados neste artigo. A fim de compor uma análise comparativa entre as ferramentas observadas, é preciso considerar que o conceito de sustentabilidade no qual cada ferramenta se baseia possui divergências de escopo, aplicação, requisitos de informação, responsabilidade pela aplicação e forma de comparação das informações. Desta forma a análise está baseada nas verificações a respeito da 
disposição e dos fatores abordados pelas ferramentas para a composição de suas análises.

Os níveis de análise propostos foram dispostos de acordo com as perspectivas da sustentabilidade: Sociedade, Economia e Meio Ambiente; posteriormente os elementos inerentes de cada dimensão foram reagrupados em categorias que representam abordagens similares. Traçando um paralelo entre as ferramentas apresentadas, no nível de análise (meio ambiente), é possível verificar dez perspectivas as quais apresentam maiores similaridades entre os fatores apontados. Nesse sentido, as categorias que se relacionam com a perspectiva meio ambiente são: terra, água, ar, espécies animais, energia, resíduos, cultivo, extração, emissões e acomodações. Com relação ao nível de análise sociedade, pode-se verificar nove categorias as quais visam representar maiores similaridades entre os fatores apontados. Desse modo, as categorias que possibilitam a análise da dimensão sociedade são: saúde, emprego, empregabilidade, educação, ciência e tecnologia, instituições públicas, infraestrutura básica, segurança, políticas, leis e gestão pública.

A análise conjunta das ferramentas abordadas, sobre o nível de análise economia, possibilita a verificação da síntese das duas dimensões apresentadas nas ferramentas em apenas uma, tendo em vista que a mesma apresenta similaridade entre os fatores apontados pelas ferramentas. Nessa abordagem, a categoria mencionada é denominada economia interna. O Quadro 4, resume as categorias de análise no contexto proposto (Sustentabilidade).

\begin{tabular}{|c|c|c|c|}
\hline Nível de análise & Categorias & Ferramentas & Autores \\
\hline \multirow{10}{*}{ Meio Ambiente } & Terra & \multirow{20}{*}{ EF, BS e DS } & \multirow{20}{*}{$\begin{array}{l}\text { Wackernagel e Rees (1996), Hardi } \\
\quad \text { (2000) e Prescott-Allen (1997) }\end{array}$} \\
\hline & Água & & \\
\hline & $\mathrm{Ar}$ & & \\
\hline & Espécies animais & & \\
\hline & Energia & & \\
\hline & Resíduos & & \\
\hline & Cultivo & & \\
\hline & Extração & & \\
\hline & Emissões & & \\
\hline & Acomodações & & \\
\hline \multirow{10}{*}{ Sociedade } & Saúde & & \\
\hline & Emprego & & \\
\hline & Empregabilidade & & \\
\hline & Educação & & \\
\hline & Ciência e Tecnologia & & \\
\hline & Instituições públicas & & \\
\hline & Infraestrutura básica & & \\
\hline & Segurança & & \\
\hline & Políticas & & \\
\hline & Leis & & \\
\hline
\end{tabular}




\begin{tabular}{|c|c|c|c|}
\hline & Gestão pública & & \\
\hline Economia & Economia Interna & BS e DS & $\begin{array}{c}\text { Hardi (2000) e Prescott-Allen } \\
\text { (1997) }\end{array}$ \\
\hline
\end{tabular}

Quadro 4 - Análise comparativa da sustentabilidade.

Fonte: Os autores.

\subsection{Sobreposições, Lacunas e Relações entre a Análise da Competitividade e da Sustentabilidade}

Frente à reorganização dos elementos nas categorias propostas para a análise integrada da sustentabilidade e da competitividade é possível verificar algumas sobreposições, lacunas e relações entre os elementos de análise dos dois campos de conhecimento. Visando demonstrar os pontos de convergência e divergência entre as dimensões e categorias foi utilizado o diagrama de afinidades.

Em nível da perspectiva meio ambiente, as categorias terra, água, ar e espécies animais objetivam a verificação de elementos que apontem a diversidade e a qualidade dos fatores aos quais cada uma se refere. Com a averiguação desses elementos, é possível a análise do estado atual da qualidade do meio ambiente de uma determinada cidade. É possível observar que nenhum dos modelos da competitividade analisados elenca fatores ou dimensões para a verificação de como o meio ambiente pode interferir na competitividade de uma cidade.

Em relação à análise da sustentabilidade, a maneira como os recursos são empregados em uma cidade pode ser considerada através da observação das dimensões e fatores elencados pelas ferramentas analisadas. Assim sendo todas as ferramentas de análise da sustentabilidade demonstram preocupações com a análise da maneira como os recursos são empregados.

Por outro lado, os modelos de análise da competitividade abordados neste estudo, não apresentam dimensões ou fatores que possam verificar como a utilização de recursos (energia, resíduos, cultivo, extração, emissões e acomodações), em uma determinada cidade, afeta a competitividade da mesma. Alguns fatores como produção do modelo Diamante, produtividade do modelo IMD e sofisticação dos negócios no modelo GDI, entre outros, apesar de relacionados ao tema, não demonstram objetivos similares em sua verificação.

Com relação ao nível de emprego e empregabilidade de uma determinada cidade, as ferramentas de análise da sustentabilidade elencam fatores como taxa de desemprego da ferramenta Dashboard of sustainability (DS) e pobreza, da ferramenta Barometer of sustainability (BS), com o intuito de verificar o comportamento de tal fator (emprego). É importante salientar que a ferramenta Ecological footprint (EF) não apresenta fatores que possam ser relacionados com a verificação do nível de emprego ou empregabilidade de uma cidade. Os modelos de análise da competitividade em relação à verificação destes elementos são mais específicos e apresentam fatores como eficiência do mercado de trabalho, do modelo GCR, e emprego, do modelo IMD. Nesse contexto, os modelos preocupam-se em como os níveis de emprego e 
empregabilidade de uma cidade são capazes de interferir na competitividade da mesma.

Em relação à saúde, as ferramentas de sustentabilidade, abordadas neste estudo, apresentam vários fatores para sua verificação. $O$ objetivo dessas ferramentas, ao analisarem o nível de saúde das pessoas de uma cidade, é apontar como o acesso à saúde afeta as atividades de uma sociedade. A saúde também é considerada nos modelos da competitividade; porém o enfoque das análises recai sobre como a qualidade de vida de pessoas que residem em cidade mais saudáveis afeta a competitividade das mesmas. Sendo assim, os modelos que apontam fatores com relação à saúde são IMD e GCR.

A educação, ciência e tecnologia são outros fatores abordados tanto nas ferramentas da sustentabilidade quanto nos modelos de análise da competitividade. Nesse sentido, em ambos os casos, as verificações buscam determinar como o nível de escolaridade e o desenvolvimento científico e tecnológico de uma cidade afetam as suas atividades.

A verificação de como a disposição das instituições públicas interferem em uma sociedade é comum tanto nas ferramentas da sustentabilidade quanto nos modelos da competitividade. Outra preocupação similar existente, não só na verificação da competitividade mas também na de sustentabilidade, com base nas ferramentas e modelos analisados, é a infraestrutura básica. Quando o foco da análise se refere aos níveis de proteção das pessoas em relação a desastres ambientais e crimes, a segurança é abordada apenas nas ferramentas de sustentabilidade. Em relação à competitividade, tal preocupação não é observável nos modelos analisados neste estudo.

A economia interna é uma questão abordada na análise da competitividade. Fatores, como economia doméstica, desenvolvimento do mercado financeiro e tamanho da dívida pública, são considerados nesta análise em relação aos modelos da sustentabilidade. A economia interna também é considerada; alguns fatores apontados são produto interno bruto (per capita), sistema financeiro e inflação.

Contudo, a economia externa é uma preocupação dos modelos de análise da competitividade, mas não das ferramentas da sustentabilidade. $\mathrm{Na}$ análise da competitividade, esse é um fator apontado pelos autores abordados como de alta relevância, onde sua análise deve ocorrer de forma inerente a mesma, ou seja, a atividade econômica externa às regiões precisa ser considerada tanto como um elemento balizador quanto catalizador da competitividade. Já na análise da sustentabilidade as verificações neste sentido são vistas de forma adjacente, ou seja, como um contexto onde o conjunto das atividades econômicas regionais se desenvolvem.

A análise referente aos fatores políticas, leis e gestão pública é verificada em ambos os contextos. No caso da competitividade os modelos GDI, IMD e Conexão da competitividade nacional e da firma; já no caso da sustentabilidade, as ferramentas Barometer of sustainability (BS) e Dashboard of sustainability (DS) elencam fatores, com o 
intuito de verificar como as características desses aspectos impactam as atividades de uma sociedade.

Os fatores socioculturais que buscam verificar como as normas e padrões inerentes às sociedades, assim como a capacidade de articulação dos atores sociais, impactam as atividades de uma sociedade, constituem uma preocupação somente dos modelos da competitividade. Tal preocupação é exposta nos modelos GDI e Conexão da competitividade nacional e da firma. Isso porque, nos modelos de análise da sustentabilidade apenas o fator sistema de crenças e valores é apontado pela ferramenta Barometer of sustainability (BS).

Os fatores externos às empresas visam a medir as características dos mercados nos quais as empresas operam. Nesse contexto estão os modelos IMD, Diamante, Conexão da competitividade nacional e da firma e GCR. Já as ferramentas da sustentabilidade não elencam fatores com o objetivo de realizar verificações similares.

A verificação dos fatores internos às empresas objetiva a análise de como a gestão e a organização das empresas interferem em uma sociedade. Com isso apenas os modelos da competividade apresentam fatores relacionados a esse objetivo. $\mathrm{O}$ Quadro 5 apresenta as semelhanças entre as categorias de análise da competitividade e da sustentabilidade.

Levando em consideração as inter-relações propostas, pode-se estabelecer, com base na análise das considerações dos autores das ferramentas e modelos analisados sobre o tema (Competitividade e Sustentabilidade), cinco dimensões que permitem a análise da competitividade das cidades que simultaneamente abrangem os elementos da sustentabilidade.

Uma dessas dimensões pode ser caracterizada como estrutural, pois compreende as variáveis que afetam as características do ambiente competitivo e, no presente contexto de análise, abrange também a categoria que reúne elementos da competitividade e da sustentabilidade assinalados como economia interna e economia externa.

A dimensão empresas tem por finalidade elencar as variáveis que incluem o contexto de atuação interno às empresas. Nesse sentido, essa dimensão compreende a categoria que reúne os fatores de análise da competitividade e da sustentabilidade relacionados às questões internas das empresas.

No caso da dimensão caracterizada como sociedade, são consideradas as características sociais que compreendem uma determinada cidade. O objetivo de tal dimensão é reunir os elementos da competitividade e da sustentabilidade que foram agregados nas categorias que representam as questões sociais. Estas categorias são fatores socioculturais, políticas, leis, gestão pública, emprego, segurança, saúde, educação, tecnologia, infraestrutura básica e instituições.

Outra dimensão que reúne elementos da sustentabilidade na análise da competitividade das cidades, é a dimensão meio ambiente. Nesse caso, a mesma se refere à caracterização da qualidade do meio ambiente em uma determinada cidade, 
e as categorias reunidas nessa dimensão são água, terra, ar e espécies e representam a reunião de elementos que possuem origem nas ferramentas de sustentabilidade.

\begin{tabular}{|c|c|c|}
\hline Categorias & Competitividade & Sustentabilidade \\
\hline Água & & $x$ \\
\hline $\mathrm{Ar}$ & & $x$ \\
\hline Terra & & $x$ \\
\hline Espécies Animais & & $x$ \\
\hline Energia & & $x$ \\
\hline Resíduos & & $x$ \\
\hline Cultivo & & $x$ \\
\hline Extração & & $x$ \\
\hline Emissões & & $x$ \\
\hline Acomodações & & $x$ \\
\hline Emprego & $x$ & $x$ \\
\hline Empregabilidade & $x$ & $x$ \\
\hline Saúde & $x$ & $x$ \\
\hline Educação & $x$ & $x$ \\
\hline Ciência e Tecnologia & $x$ & $x$ \\
\hline Instituições Públicas & $x$ & $x$ \\
\hline Infraestrutura Básica & $x$ & $x$ \\
\hline Segurança & & $x$ \\
\hline Economia Interna & $x$ & $x$ \\
\hline Economia Externa & $x$ & \\
\hline Politicas & $x$ & $x$ \\
\hline Leis & $x$ & $x$ \\
\hline Gestão Pública & $x$ & $x$ \\
\hline Fatores Socioculturais & $x$ & \\
\hline Fatores Externos às Empresas & $x$ & \\
\hline Fatores Internos às Empresas & $x$ & \\
\hline
\end{tabular}

Quadro 5 - Sobreposições, lacunas e relações entre competitividade e sustentabilidade.

Fonte: Os autores.

Por fim, a dimensão eficiência do uso de recursos visa a representação da maneira como os recursos são empregados em uma determinada cidade, relacionando-se com a categoria utilização de recursos. Tal categoria reúne variáveis que possibilitam a verificação de como os recursos estão sendo empregados e possui origem nas ferramentas de análise da sustentabilidade. 
O Quadro 6 expõe as dimensões propostas e suas respectivas categorias. Em sequência são apresentados os procedimentos metodológicos adotados nesta pesquisa.

\begin{tabular}{|c|c|}
\hline Dimensões & Categorias \\
\hline \multirow{12}{*}{ Sociedade } & Fatores socioculturais. \\
\hline & Políticas \\
\hline & Leis \\
\hline & Gestão pública \\
\hline & Emprego \\
\hline & Empregabilidade \\
\hline & Segurança \\
\hline & Saúde \\
\hline & Educação \\
\hline & Ciência e Tecnologia \\
\hline & Infraestrutura básica \\
\hline & Instituições públicas \\
\hline \multirow{2}{*}{ Sistêmicos } & Economia interna \\
\hline & Economia externa \\
\hline \multirow{4}{*}{ Meio-ambiente } & Terra \\
\hline & Água \\
\hline & $\mathrm{Ar}$ \\
\hline & Espécies \\
\hline \multirow{6}{*}{ Eficiência do uso de recursos } & Energia \\
\hline & Resíduos \\
\hline & Cultivo \\
\hline & Extração \\
\hline & Emissões \\
\hline & Acomodações \\
\hline \multirow{2}{*}{ Empresas } & Fatores internos às empresas. \\
\hline & Fatores externos as empresas \\
\hline
\end{tabular}

Quadro 6 - Dimensões e categorias propostas para análise simultânea da competitividade e sustentabilidade das cidades.

Fonte: Os autores.

\section{PROCEDIMENTOS METODOLÓGICOS}

Buscando atender o objetivo proposto no estudo, optou-se pelo delineamento de uma pesquisa exploratória, de acordo com Sampiere, Colado e Lucio (2006). O presente artigo possui enfoque qualitativo para atender os requisitos de seu objetivo. 
A unidade de análise do presente estudo é constituída pelas dimensões e os fatores de análise da competitividade e sustentabilidade que abrangem o contexto das cidades. Desta maneira, visa-se analisar e compreender a relevância dos elementos da competitividade e da sustentabilidade propostos para realização de análises conjuntas, envolvendo os dois temas, na busca de uma visão abrangente do desenvolvimento das cidades. Em face da unidade de análise abordada, optou-se por um estudo de corte transversal de acordo com Malhotra (2001), já que os dados foram extraídos da amostra apenas uma vez.

Destaca-se que o presente artigo não busca estabelecer uma proposta de medição e avaliação do desempenho do ambiente das cidades nos temas pesquisados, mas sim, as relações entre eles, para que assim seja possível o desenvolvimento de estratégias que possibilitem que as cidades se tornem mais competitivas e sustentáveis.

A fase empírica da pesquisa foi realizada em duas etapas. Na primeira etapa foram realizadas entrevistas presenciais como fontes relevantes de dados neste estudo, pois se tratou da percepção das pessoas (atores sociais e especialistas) sobre o tema proposto na pesquisa. Além disso, os documentos apresentados pelos entrevistados foram utilizados no estudo como forma de sustentação de suas considerações. Posteriormente, na segunda etapa, foram utilizados os mapas cognitivos como forma de tecer representações explícitas das relações causais descritas pelos respondentes (pensamento reflexivo), tal como proposto por Nelson, Nelson e Armstrong (2000). Neste caso também foram pesquisados atores sociais das cidades e especialistas nos temas.

Os respondentes foram escolhidos por conveniência e estão agregados em duas categorias: 4 Especialistas, para que fosse possível verificar os fatores de influência na competitividade e sustentabilidade com base no ponto de vista teórico; e 8 Atores sociais, para que fosse possível verificar os fatores baseados na experiência prática e no conhecimento empírico de cada um.

Para a análise dos dados coletados na primeira etapa da pesquisa (entrevistas) foi utilizado o método de Análise de Conteúdo, de acordo com Bardin (1979). No que concerne aos mapas cognitivos, estes foram do tipo Mapas Causais, onde os entrevistados tiveram de estruturar seu raciocínio em termos de relações existentes entre os elementos de competitividade e sustentabilidade considerados, o que conduziu a uma melhor compreensão sobre o entendimento e relevância da problemática pelos respondentes. A construção dos Mapas seguiu um método específico (PIDD, 2001 e BASTOS, 2002). Apresentam-se a seguir os resultados obtidos na pesquisa de campo e sua análise.

\section{APRESENTAÇÃO E DISCUSSÃO DOS RESULTADOS}

Este tópico acha-se estruturado em entrevistas e mapas cognitivos. No Quadro 7 a seguir é apresentada uma breve caracterização dos participantes da pesquisa 
empírica, tanto dos respondentes das entrevistas como dos desenvolvedores dos Mapas Cognitivos.

\begin{tabular}{|c|c|c|c|c|c|c|}
\hline 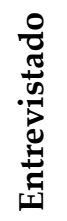 & 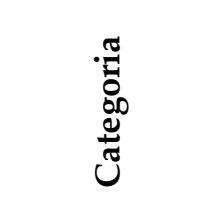 & 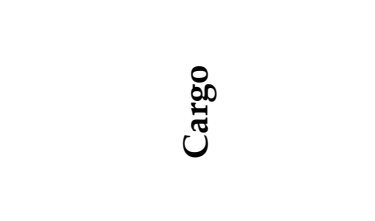 & 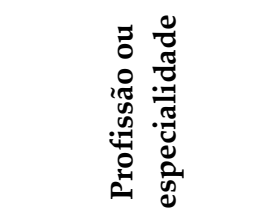 & 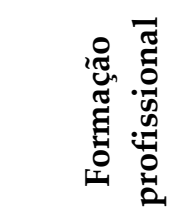 & 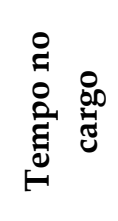 & 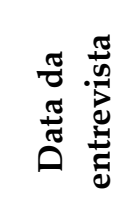 \\
\hline 1 & Especialista & Professor & COREDE & Mestrado & $\begin{array}{c}23 \\
\text { anos }\end{array}$ & $16 / 12 / 12$ \\
\hline 2 & Especialista & Professor & COREDE & $\begin{array}{l}\text { Pós- } \\
\text { doutorado }\end{array}$ & $\begin{array}{c}28 \\
\text { anos }\end{array}$ & $15 / 12 / 12$ \\
\hline 3 & Especialista & Pesquisadora & Sustentabilidade & Mestrado & 8 anos & $30 / 11 / 12$ \\
\hline 4 & Especialista & Professor & Sustentabilidade & Doutorado & $\begin{array}{c}15 \\
\text { anos }\end{array}$ & $13 / 11 / 12$ \\
\hline 5 & Ator Social & Prefeito & Comerciário & $\begin{array}{l}\text { Ensino } \\
\text { Médio }\end{array}$ & $\begin{array}{c}12 \\
\text { anos }\end{array}$ & $18 / 12 / 12$ \\
\hline 6 & Ator Social & Prefeito & Bancário & $\begin{array}{l}\text { Ensino } \\
\text { Médio }\end{array}$ & 4 anos & $25 / 11 / 12$ \\
\hline 7 & Ator Social & Prefeito & $\begin{array}{l}\text { Funcionário } \\
\text { Público }\end{array}$ & Graduação & 3 anos & $17 / 10 / 12$ \\
\hline 8 & Ator Social & Vereadora & Professora & $\begin{array}{l}\text { Pós- } \\
\text { Graduação }\end{array}$ & 4 anos & $26 / 10 / 12$ \\
\hline 9 & Ator Social & Vereadora & Professora & Graduação & 4 anos & $30 / 10 / 12$ \\
\hline 10 & Ator Social & $\begin{array}{l}\text { Sec. Municip. de } \\
\text { Desenvolv. Econômico }\end{array}$ & $\begin{array}{l}\text { Funcionário } \\
\text { Público }\end{array}$ & Técnico & 4 anos & $03 / 12 / 12$ \\
\hline 11 & Ator social & $\begin{array}{l}\text { Delegada Regional do } \\
\text { Trabalho }\end{array}$ & Advogada & Graduação & 1 ano & $11 / 12 / 12$ \\
\hline 12 & Ator social & $\begin{array}{l}\text { Presidente da Câm. de } \\
\text { Com. Ind. e Serv. }\end{array}$ & Empresária & $\begin{array}{l}\text { Ensino } \\
\text { Médio }\end{array}$ & 2 anos & $10 / 12 / 12$ \\
\hline
\end{tabular}

Legenda: COREDE - Conselho Regional de Desenvolvimento

Quadro 7 - Caracterização dos entrevistados.

Fonte: Os autores a partir da pesquisa empírica.

\subsection{Análise das entrevistas}

A verificação a respeito da competitividade e da sustentabilidade, com base nas abordagens dos atores sociais entrevistados, permite a observação de uma aproximação dos conceitos empregados na pesquisa para fins da proposta da estrutura de análise, em relação a noção empregada pelos atores sociais sobre esses temas.

O Quadro 8 apresenta as relações identificadas pelos entrevistados. Cabe salientar a complementaridade entre os conceitos de sustentabilidade e competitividade, seja a partir da compreensão dos atores sociais entrevistados, seja pelas abordagens utilizadas no presente estudo. Nesse sentido, as abordagens 
demonstram uma aproximação possível entre as noções de competitividade e sustentabilidade.

\begin{tabular}{|c|l|l|}
\hline Abor. & \multicolumn{1}{|c|}{ Atores sociais } & \multicolumn{1}{c|}{ Conceitos utilizados } \\
\hline & $\begin{array}{l}\text { Capacidade de aproveitamento da localização } \\
\text { geográfica e do patrimônio natural para que, }\end{array}$ & $\begin{array}{l}\text { Capacidade de articulação de fatores } \\
\text { com o objetivo de atrair e desenvolver } \\
\text { uma estrutura adequada para a }\end{array}$ \\
em conjunto com o oferecimento de benefícios, \\
promoção do desenvolvimento.
\end{tabular}

Quadro 8 - Conceitos de competitividade e sustentabilidade empregados no estudo e os atores sociais pesquisados.

Fonte: Os autores a partir da pesquisa empírica.

Este posicionamento é corroborado pelas considerações dos especialistas. As considerações dos mesmos podem ser observadas no Quadro 9.

\begin{tabular}{|c|l|}
\hline Entrevistado & \multicolumn{1}{c|}{ Considerações } \\
\hline $\mathbf{1}$ & "A sustentabilidade preserva a competividade" \\
\hline $\mathbf{2}$ & $\begin{array}{l}\text { "O que se espera é que as cidades sejam sustentáveis, e que essa sustentabilidade } \\
\text { seja capaz de atrair e reter investimentos" }\end{array}$ \\
\hline $\mathbf{3}$ & "A cidade, sendo sustentável, vai ser mais competitiva" \\
\hline $\mathbf{4}$ & $\begin{array}{l}\text { "Se a cidade não for competitiva e sustentável, ela não estará cumprindo o seu } \\
\text { papel" }\end{array}$ \\
\hline
\end{tabular}

Quadro 9 - Competitividade e sustentabilidade conforme os especialistas entrevistados.

Fonte: Os autores a partir da pesquisa empírica.

Com isso, os entrevistados foram questionados a respeito da possível influência das dimensões, e suas categorias, em relação à competitividade e sustentabilidade das cidades. Com relação à dimensão estrutural, os atores sociais entrevistados acreditam que suas categorias economia interna e economia externa possuem influência na competitividade e na sustentabilidade das cidades.

A respeito da dimensão sociedade, tanto os atores sociais como os especialistas entrevistados acreditam que as doze categorias elencadas são capazes de interferir na competitividade e na sustentabilidade de uma cidade.

Sobre a dimensão empresas, todos os entrevistados pensam que suas categorias, fatores internos às empresas e fatores externos às empresas, apresentam 
influência no contexto de análise proposto. Ressalta-se que de acordo com os atores sociais as formas pelas quais as empresas são geridas é que determinam o quanto elas serão sustentáveis; este posicionamento é similar para os especialistas entrevistados.

Com relação à dimensão meio ambiente, os entrevistados verificam que a qualidade e a diversidade dos elementos abordados interferem nas cidades de forma positiva, quando representam benefícios socioeconômicos, ou negativa, quando tais fatores são abordados como problemas a serem superadas pela coletividade (empresas, sociedade civil, governos e outros).

Para os entrevistados, a forma como os recursos são empregados, ou seja, a dimensão eficiência do uso de recursos, é relevante no contexto de análise proposto, tendo em vista que a mesma é capaz de determinar o quanto uma cidade é capaz de gerir e empregar os seus recursos de forma eficiente.

\subsection{Análise dos mapas cognitivos}

Com base na metodologia proposta, foi solicitado aos entrevistados que desenvolvessem um mapa cognitivo que contivesse os elementos abordados, para que fosse possível verificar os relacionamentos existentes entre os diversos fatores desenvolvidos. A análise dos mapas cognitivos é realizada, a fim de que seja possível averiguar as relações lógicas, principalmente de causa-e-efeito, observadas pelos entrevistados em relação às categorias de análise, ou seja, se os mesmos de fato percebem a pertinência da estrutura de análise proposta neste estudo.

A agregação dos mapas cognitivos dos especialistas e dos atores sociais possibilitou a verificação de como as categorias de análise se relacionam, permitindo, com isso, a realização de análises conjuntas da competitividade e da sustentabilidade das cidades.

A construção dos mapas agregados dos especialistas e atores sociais permite verificar a relevância de elementos como fatores socioculturais, que influenciam oito categorias, instituições públicas, que influenciam seis categorias e gestão pública que influencia cinco categorias.

Além disso, destaca-se também algumas categorias-fim, como as categorias fatores externos às empresas, influenciada por sete categorias, emprego, influenciada por seis categorias e empregabilidade influenciada por cinco outras categorias. $\mathrm{O}$ mapa cognitivo agregado de todos os dos entrevistados pode ser observado na Figura 1.

Nota-se que todas as categorias teoricamente desenvolvidas foram incluídas nos mapas produzidos. Com isso é possível considerar a pertinência das mesmas conforme proposto no estudo realizado. Verifica-se também, com base nos mapas cognitivos: (i) que é possível desenvolver uma estrutura de análise combinada da competitividade e sustentabilidade, mesmo que ambos os campos aparentemente se mostrem contraditórios, (ii) as categorias chave propostas são capazes de influenciar muitas outras categorias, (iii) as categorias fim, demonstram os resultados 
teoricamente possíveis de serem alcançados, através da realização de ações em categorias chave e meio. De forma complementar, ressalta-se que o desenvolvimento de uma cidade possui caráter multidisciplinar e, por consequência, não parece poder ocorrer com a realização de ações em uma única categoria ou dimensão, mas sim pelo empreendimento de esforços multidisciplinares e simultâneos, logicamente encadeados, em diversas áreas do contexto analisado.

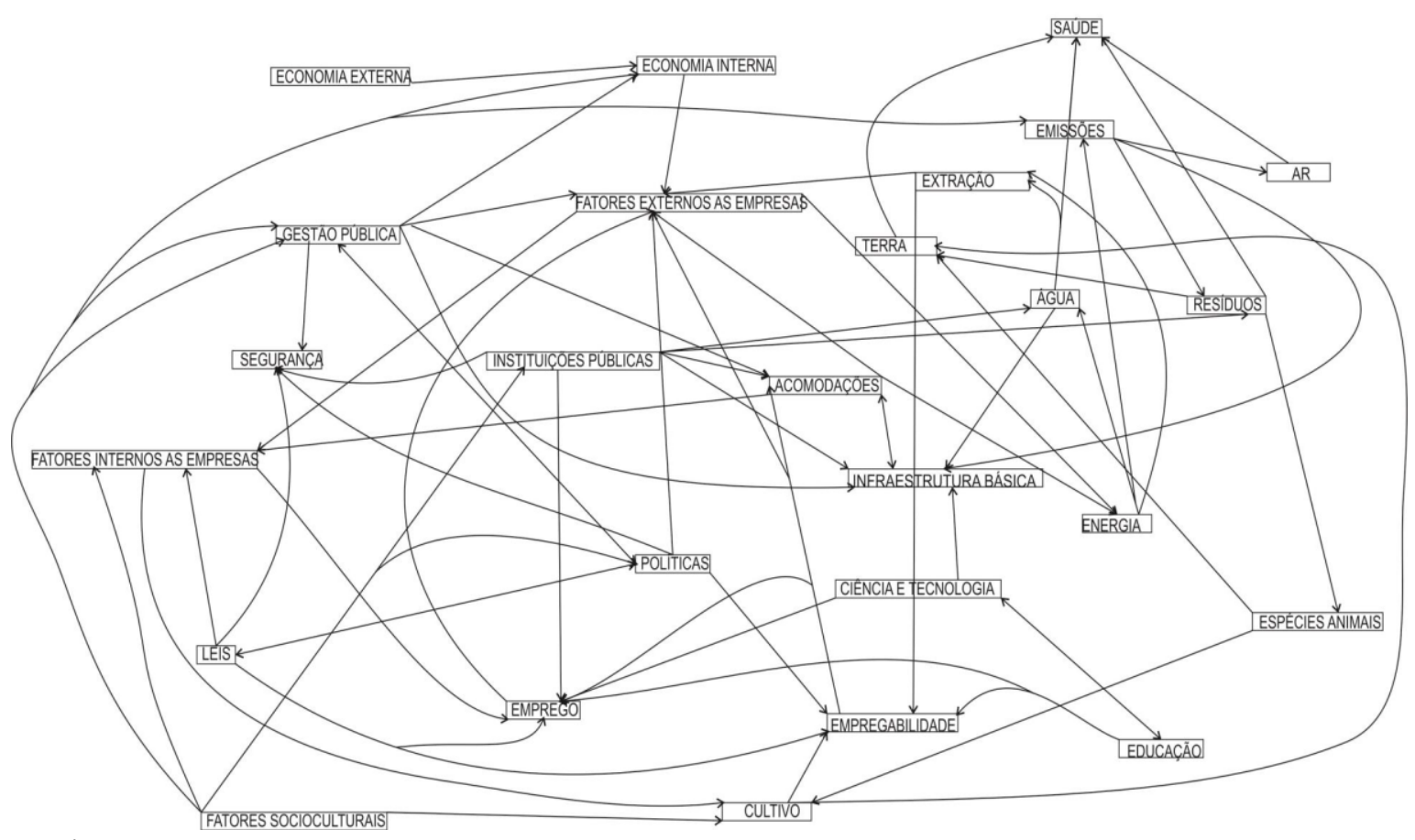

Figura 1 - Mapa cognitivo agregado atores sociais e especialistas.

Fonte: Os autores a partir da pesquisa empírica.

\section{CONSIDERAÇÕES FINAIS}

Respeitando-se os paradigmas da Maximização do Lucro dos Shareholders e da Responsabilidade Social Corporativa, e levando em consideração as abordagens conceituais a respeito da competitividade e sustentabilidade, é possível verificar algumas relações entre os elementos da competitividade e da sustentabilidade das cidades. Não se trata de escolher entre um paradigma e outro, mas sim de conciliar as diferenças e promover novas formas de pensar.

A reflexão proposta neste artigo - Como contemplar noções de sustentabilidade na análise da competitividade sistêmica das cidades? - deixa evidente que tal diálogo não só é possível como necessário. Não fazê-lo, é manter as iniciativas de sustentabilidade, capitaneadas por diferentes atores sociais (Governo, Iniciativa privada e Sociedade Civil) desconectadas, e obscurecer muitas das grandes oportunidades para geração de benefícios para sociedade. A partir da análise e resultados obtidos nesta pesquisa, algumas conclusões relevantes podem ser estabelecidas, como: 
(a) Constata-se que a análise da competitividade e da sustentabilidade das cidades pode ser realizada conjuntamente, conforme demonstrado pelos entrevistados; (b) Percebe-se que as diferenças de posições dos atores sociais e especialistas sobre a maneira como cada categoria interfere (positiva ou negativamente) na competitividade e sustentabilidade das cidades, sofrem impacto das características históricas, socioculturais, econômicas e ambientais nas quais eles estão inseridas. Contudo, mesmo em contextos diferentes, a grande maioria dos entrevistados entende de forma similar a relevância das categorias para a realização da análise proposta; (c) Verifica-se que os fatores competitivos e sustentáveis mais relevantes para as cidades (categorias-chave) no contexto atual, segundo os entrevistados, estão mais vinculados à interferência dos fatores socioculturais, gestão pública e formas de coordenação entre a sociedade civil, poder público e empresas, mediante as instituições públicas; (d) As categorias-chave mostram-se fundamentais como ponto de partida para a estruturação de estratégias de desenvolvimento integradas das cidades pois representam a base para o desenvolvimento das demais, (e)Ainda, verificou-se que os entrevistados foram capazes de identificar as relações entre as categorias, e o grau de influência das mesmas, pelo emprego dos mapas cognitivos como metodologia de pesquisa.

Assim levando-se em conta a possibilidade de contribuições práticas e teóricas promovidas pela verificação conjunta da competitividade e sustentabilidade, algumas limitações devem ser levantadas. A quantidade de entrevistados na categoria atores sociais, foi impactada pelo período eleitoral ocorrido de forma concomitante à realização das entrevistas, o que dificultou sobremaneira os contatos. Com relação aos especialistas, a greve das instituições federais, ocorrida no mesmo período, dificultou que mais entrevistas fossem realizadas junto a esta categoria. Ressalva-se que as relações entre os elementos estabelecidas neste trabalho podem se alterar ao longo do tempo, o que indica a relevância de serem realizadas, no futuro, novas verificações sobre o tema. Destaca-se também que foram entrevistados apenas atores sociais de cidades do Rio Grande do Sul, outras regiões possuem culturas, histórias e recursos naturais diferentes que podem interferir nos resultados apresentados.

Sugere-se que em estudos futuros, desenvolva-se uma pesquisa similar utilizando-se o método quantitativo, com o objetivo de verificar se a estrutura de análise proposta aplica-se às cidades de forma mais ampla. Por fim, o aprofundamento da discussão sobre a intensidade de influência das categorias abordadas nas cidades, poderia ampliar o entendimento sobre as relações existentes entre elas (categorias), bem como ampliar as verificações a respeito da importância de cada uma para a competitividade e sustentabilidade das cidades. Além disso, o aprofundamento da discussão a respeito de uma provável sequência de ações capazes de alavancar a competitividade das cidades, considerando os elementos da sustentabilidade, seria capaz de apontar um caminho para o desenvolvimento das 
regiões de maneira socialmente justa, ambientalmente responsável e economicamente viável.

\section{REFERÊNCIAS}

BASTOS, A. V. B. Mapas cognitivos e pesquisa organizacional: explorando aspectos metodológicos. In: Estudos de Psicologia. p. 65-77, 2002.

CHIKÁN, A. National and firm competitiveness: a general research model. Competitiveness Review: An International Business Journal. Vol. 18, 2008.

COUTINHO, L. G., FERRAZ, J. C. Estudo da competitividade da indústria brasileira. 4 $4^{\mathrm{a}}$ Ed. São Paulo: Papirus, 2002.

DORNELES, D. R. Análise da competitividade em empresas de desenvolvimento de software instaladas no TECNOPUC no Rio Grande do Sul. - Porto Alegre, 2011.

ELKINGTON, J. Cannibals with forks: the triple bottom line of $21^{\text {st }}$ century business. Gabriola Island: New society publishers, 1998.

ESTERHUIZEN, D.; ROOYEN, J. V.; D'HAESE, L. An evaluation of the competitiveness of the agribusiness sector in South Africa. Advances in Competitiveness Research - ACR. Vol. 16 (1\&2), 2008.

ESSER, K. HILLEBRAND, W. MESSNER, D. MEYER-STAMER, J. Systemic Competitiveness, New Governance Patterns for Industrial Development, Londres, 1996.

FEUER, R. CHAHARBACHI, K. Defining Competitiveness: A holistic approach. Management Descision, Vol. 32, № 2, p. 49 - 58, 1994.

FRIEDMAN, M. The social responsibility of business is to increase its profits. The New York Times Magazine, Sep 13. p. 122-126, 1971.

GARRIGA, E; MELÉ, D. Corporate Social Responsibility Theories: Mapping the Territory. Journal of Business Ethics. nº 53, p. 51-71, 2004.

HUSTED, B.; ALLEN, D. Corporate Social Strategy in Multinational Enterprises: Antecedents and Value Creation. Journal of Business Ethics, Vol. 74, no 4, p. 345-361, 2007.

JENSEN, M. C. Value maximization, stakeholder theory, and the corporate objective function. Journal of Applied Corporate Finance, v. 14, n. 3, p. 8-21, 2001. 
KRISHNAN, S. In Defense of Social Responsibility of Business. Mustang Journal of Business \& Ethics. 2011.

MACHADO-DA-SILVA, C. L.; BARBOSA, S. L. Estratégia, fatores de competitividade e contexto de referência: uma análise arquetípica. RAC, v.6, n. 3, Set/Dez. 2002: 7-32.

MALHOTRA, N. Pesquisa de Marketing: uma orientação aplicada. 3. ed. - Porto Alegre: Bookman, 2001.

PIDD, M. Modelagem empresarial: ferramentas para a tomada de decisão. Porto Alegre: Bookman, 2001.

PRAHALAD, C. K.; HAMEL, G. The Core Competence of the Corporation. Harvard Business Review, 1990.

PIDD, M. Modelagem empresarial: ferramentas para a tomada de decisão. Porto Alegre: Bookman, 2001.

PORTER, M. E. The Competitive Advantage of Nations. The Free Press, New York, 1990.

PORTER, M. E., KRAMER, M. R. Strategy \& Society: The link between competitive advantage and Corporate Social Responsibility. Harvard Business Review. December, 2006.

RAFFESTIN, C. Por uma geografia do poder. São Paulo: Ática, 1993.

SAMPIERI, R; COLLADO, C; LUCIO, P. Metodologia de Pesquisa. São Paulo: McGraw-Hill, 2006.

SANTOS, M. A natureza do espaço: técnica e tempo. Razão e Emoção. 2a. Ed. São Paulo: Hucitec, 1997.

SANTOS, M.; SILVEIRA, M. L. O Brasil: Território e sociedade no início do século XXI. Rio de Janeiro: Record, 2001.

SENGE, P.; LICHTENSTEIN,B.; KAEUFER, K.; BRADBUR, H. AND CARROLL, J. Collaborating For Systemic Change. Sloan Management Review. vol.48, nº . 2, 2007.

SLACK, N. Vantagem competitiva em manufatura. São Paulo: Editora Atlas S.A. 1993.

STERNBERG, E. The stockholder concept: a mistake doctrine. Foundation for Business Responsibility. Leeds, Issue Paper, n. 4, nov. 1999. Disponível 
em:<http://papers.ssrn.com/sol3/papers.cfm?abstract_id=263144>. Acesso em: 2 jul. 2012.

VAN BELLEN, H. M. Indicadores de Sustentabilidade: uma análise comparativa. Tese (Doutorado em Engenharia de Produção) - Universidade Federal de Santa Catarina. CPGEP/UFSC, 250 p., 2002.

WAHEEDUZZAMAN, A. N. M. Competitiveness, Human Development and Inequality: A cross- national comparative inquiry. Competitiveness Review, Vol. 12, № 2, 2002. 